\title{
Cyclosporine A, a Potential Therapy of Ischemic Reperfusion Injury. A Common History for Heart and Brain
}

\author{
Norbert Nighoghossian ${ }^{a, b}$ Michel Ovize ${ }^{c}$ Nathan Mewton ${ }^{c}$ Elodie Ong ${ }^{a, b}$ \\ Tae-Hee Cho ${ }^{a, b}$ \\ a Department of Neurology, Hôpital Neurologique Pierre Wertheimer, and ${ }^{\mathrm{b}}$ Creatis CNRS UMR 5220 - INSERM \\ U1044, INSA, Université Lyon 1, and 'Hôpital Louis Pradel, Service d'Explorations Fonctionelles Cardiovasculaires, \\ Centred' Investigation Clinique and UMR1060 (CarMeN), Université Claude Bernard Lyon 1, Lyon, France
}

\author{
Key Words \\ Ischemic stroke $\cdot$ Reperfusion injury · Neuroprotection . \\ Cyclosporine
}

\begin{abstract}
Background: Ischemic stroke (IS) and acute myocardial infarction require emergency reperfusion tissue in order to improve functional outcome. Intra-arterial thrombectomy recently showed very encouraging improvement in IS patients' outcome. However, endovascular methods enhancing reperfusion may expose patients to increase in ischemic reperfusion injury. Experimental evidence indicates that brain ischemic reperfusion injury may be attenuated by ischemic pre- and postconditioning. The opening of mitochondrial permeability transition pore plays a critical role in the onset of reperfusion damage. This mechanism can be inhibited by immunosuppressive drugs like cyclosporine A (CsA). Summary: In this review, we present existing experimental and clinical data suggesting that conditioning interventions may prevent brain ischemic reperfusion injury and future challenge for neuroprotection by CsA in acute IS. Key Messages: The concept of conditioning has been recently investigated clinically but to a lesser extent in the realm of IS. Recent experimental and phase II clinical research has suggested po-
\end{abstract}

tential neuroprotective properties of cyclosporine; however, further larger clinical trials are needed to demonstrate that CsA improves clinical outcome in acute IS patients.

(C) 2016 S. Karger AG, Basel

\section{Introduction}

Ischemic stroke (IS) and acute myocardial infarction require emergency reperfusion in order to improve functional outcome. In both conditions, treatments have changed in parallel during the last 2 decades [1]. Intravenous tissue-type plasminogen activator has long been the only therapy with proven clinical benefit in patients with acute IS [2], despite incomplete benefit in patients with large cerebral artery occlusion. Although previous randomized controlled trials [3-5] did not show a benefit over standard treatment, recent studies confirm the effectiveness of this strategy [6-10]. Endovascular methods enhancing reperfusion may expose patients to increased ischemic reperfusion injury thereby hampering the benefit of recanalization by promoting hemorrhagic transformation (HT) and severe vasogenic edema both considered as markers of reperfusion injury [11-14].

\section{KARGER}

E-Mail karger@karger.com

www.karger.com/ced (c) 2016 S. Karger AG, Base

1015-9770/16/0426-0309\$39.50/0
Norbert Nighoghossian, MD, PhD

Department of Neurology

Hôpital Neurologique Pierre Wertheimer

59 Bd Pinel, Bron, FR-69777 Lyon (France)

E-Mail norbert.nighoghossian@chu-lyon.fr 
Experimental evidence indicates that brain ischemic reperfusion injury may be attenuated by ischemic preand postconditioning. Basically, brief episodes of ischemia and reperfusion applied prior to (preconditioning) or immediately after (postconditioning) the sustained artery occlusion have been shown to dramatically reduce stroke volume in animal models [15]. Experimental evidence suggests that mitochondrial permeability transition pore (MPTP) plays a critical role in this process [16]. This phenomenon occurs in the early minutes of reperfusion following a prolonged (i.e., responsible for irreversible tissue damage) ischemia; it is due to the opening in the inner mitochondrial membrane of a mega channel the MPTP that can be prevented by administration of cyclosporine A (CsA) $[17,18]$. However, the ability of any preand postconditioning intervention to attenuate reperfusion injury depends on the duration of the preceding ischemia and on the application of this intervention within a limited time window ( $<15 \mathrm{~min}$ ) following successful recanalization, in line with the therapeutic window validated by ECASS III study [19].

\section{General Background of Ischemic Reperfusion Injury in Brain and Potential Impact of CsA}

Following a prolonged interruption of cerebral perfusion, part of the neurons that lie distal to the obstructed vessel may die. Obviously, timely cerebral blood flow restoration will salvage a majority of cells that did not die by the end of the ischemia phase. Unfortunately, reperfusion may have noxious side effects and promote substantial additional brain damage termed 'reperfusion injury', that is, part of the cells that were still viable at the end of the ischemic phase, will die as a result of this second insult occurring at the onset of reflow [20,21]. Hence, the final irreversible damage observed after reperfusion following an ischemic insult results from the addition of a first damage occurring during ischemia and a second damage specifically induced by reperfusion. Noteworthy, ischemic reperfusion injury is not limited to the parenchymal and stromal tissues but also involves the cerebral vasculature [22].

The mechanism of reperfusion-induced cellular damage remains unclear. However, experimental evidence indicates a crucial role of a specific mitochondrial dysfunction named 'mitochondrial permeability transition'. At the time of reperfusion after a prolonged ischemia, abrupt matrix accumulation of $\mathrm{Ca}^{2+}$ and overproduction of reactive oxygen species (ROS) trigger the opening of a mega channel in the inner mitochondrial membrane, named the 'permeability transition pore' (PTP) $[16,23,24]$. Accordingly, during reperfusion, there is overproduction of ROS in mitochondria, which rapidly exhaust endogenous antioxidant scavenging capacity. The resulting flood of ROS directly causes oxidative damage on cellular macromolecules, such as proteins, nucleic acids and lipids, which lead to mitochondrial swelling, cell injury and death $[25,26]$.

The mechanisms of mitochondrial ROS generation during reperfusion injury may also involve changes in mitochondrial membrane potential. Hyperactive oxidative phosphorylation generates high mitochondrial membrane potentials, a condition known to generate excessive ROS. Such a state would lead to a 'burst' of ROS upon reperfusion, thereby causing structural and functional damage to the mitochondria and inducing cell death signaling that eventually culminate in tissue damage [27].

Although superoxide dismutase and NADPH (nicotinamide adenine dinucleotide phosphate) oxidase have been shown to reduce ischemic reperfusion injury in animal models $[28,29]$, the clinical benefit of antioxidant strategy has also been difficult to show in human trials as shown by SAINT I and II trials [30] and the recent URICO-ICTUS study in which the addition of uric acid to thrombolytic therapy did not increase the proportion of patients who achieved excellent outcome after stroke compared with placebo [31] despite reduced infarct growth in women with acute IS treated with alteplase [32].

CsA, apart from its immunosuppressive activity, inhibits PTP opening and reduces infarct size in animal models of cerebral ischemia [33-44]. The neuroprotective effect appears to depend on several factors, including the route of administration (intravenous (IV), intra-cerebral, ischemic preconditioning (IP) intra peritonea, intracarotid, subcutaneous, intracerebro ventricular), the dosage of CsA, the duration of ischemia, the timing of administration with respect to the onset of ischemia and of reperfusion, the nature of the ischemic model (transient middle cerebral artery occlusion (MCAO) or permanent MCAO, blood-brain barrier (BBB) permeability) and finally the association with other drugs. Preclinical data characteristics and results are summarized in table 1 and the putative mechanism of the effect of cyclosporine on PTP is shown in figure 1.

The molecular structure of the PTP remains unknown. Yet, it is accepted that cyclophilin D (CyPD), a mitochondrial matrix chaperone, is a key component of the PTP [45]. Mitochondrial $\mathrm{Ca}^{2+}$ accumulation can activate 


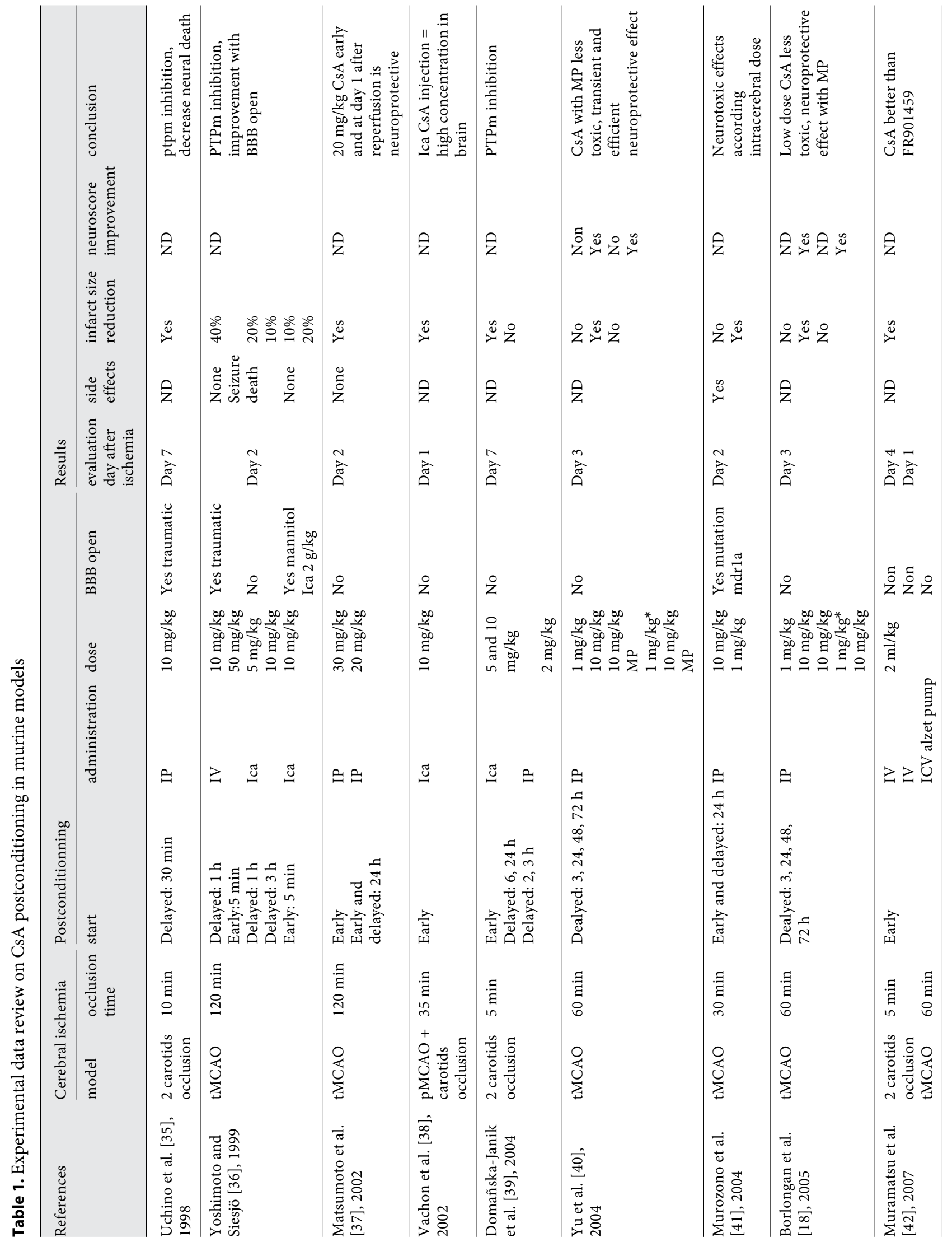




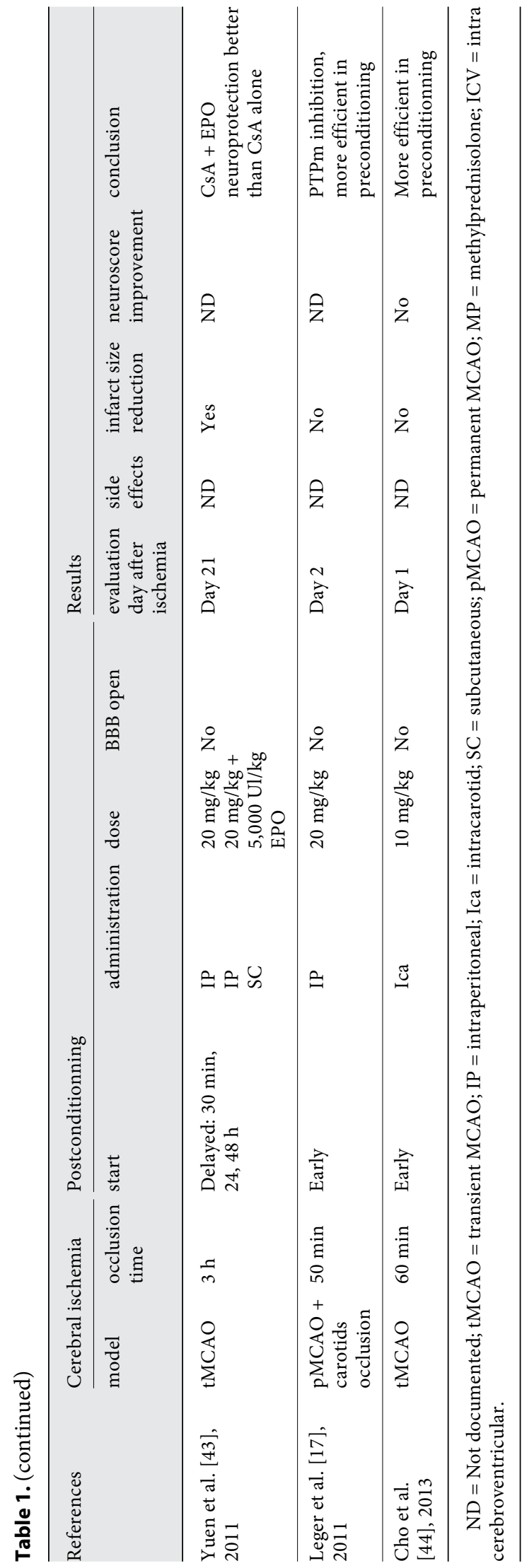

$\mathrm{CyPD}$ and subsequently trigger PTP opening. Mice lacking CyPD display a delayed opening of the PTP when $\mathrm{Ca}^{2+}$ overload is present and develop smaller cerebral infarcts after prolonged ischemia and reperfusion [46].

Ischemic reperfusion also triggers a sterile inflammatory response [47]. There is emerging evidence that CsA could induce neuroprotective effects via mechanisms different from the inhibition of PTP opening [48]. By preventing calcineurin-mediated dephosphorylation, CsA inhibits the translocation of the nuclear factor of activated T cells (NFAT) family of transcription factors to the nucleus of activated T cells. The NFAT group is involved in the transcriptional activation of the genes encoding interleukin (IL)-2, IL-4 and CD40L; thus, inhibition of the NFAT by CsA results in a specific inhibition of IL production in the T cell [49]. Inhibition of calcineurin by CsA may prevent the dephosphorylation of NOS thereby limiting glutamate neurotoxicity [50]. Endothelial cells contribute to this phenomenon by expressing adhesion molecules that facilitate leukocytes binding and infiltration into reperfused areas. Increasing evidence links the toll-like receptors (TLRs), particularly TLR2 and TLR4, to the deleterious inflammatory effects seen in ischemic reperfusion injury associated with IS [51, 52].

The activation of the phosphorylation of RISK (reperfusion injury salvage kinases) pathway including, that is, phosphatidylinositol 3-kinase/protein kinase B (PI3KAKT), of the mitogen-activated protein kinase kinase/extracellular signal regulated kinase (MEK1/2-ERK1/2) pathway and/or of signal transducer and activator of transcription 3 may play a role in postconditioning by modulating PTP opening [53-55]. Pharmacological agents targeting these pathways such as CsA may protect the brain from reperfusion injury [56-59]. The neuroprotective effect of CsA may also involve BBB permeability modulation through inhibition of cyclophilin $\mathrm{A}$ as suggested by the experimental model of traumatic brain injury [60].

\section{Conditioning Interventions to Prevent Reperfusion Injury}

\section{Mechanical Conditioning}

In 1986, Murry et al. [61], first demonstrated in the dog heart that brief episodes of ischemia with intervening reperfusion, applied before a prolonged ischemic insult, resulted in a dramatic reduction of infarct size; they named this phenomenon 'ischemic preconditioning'. 


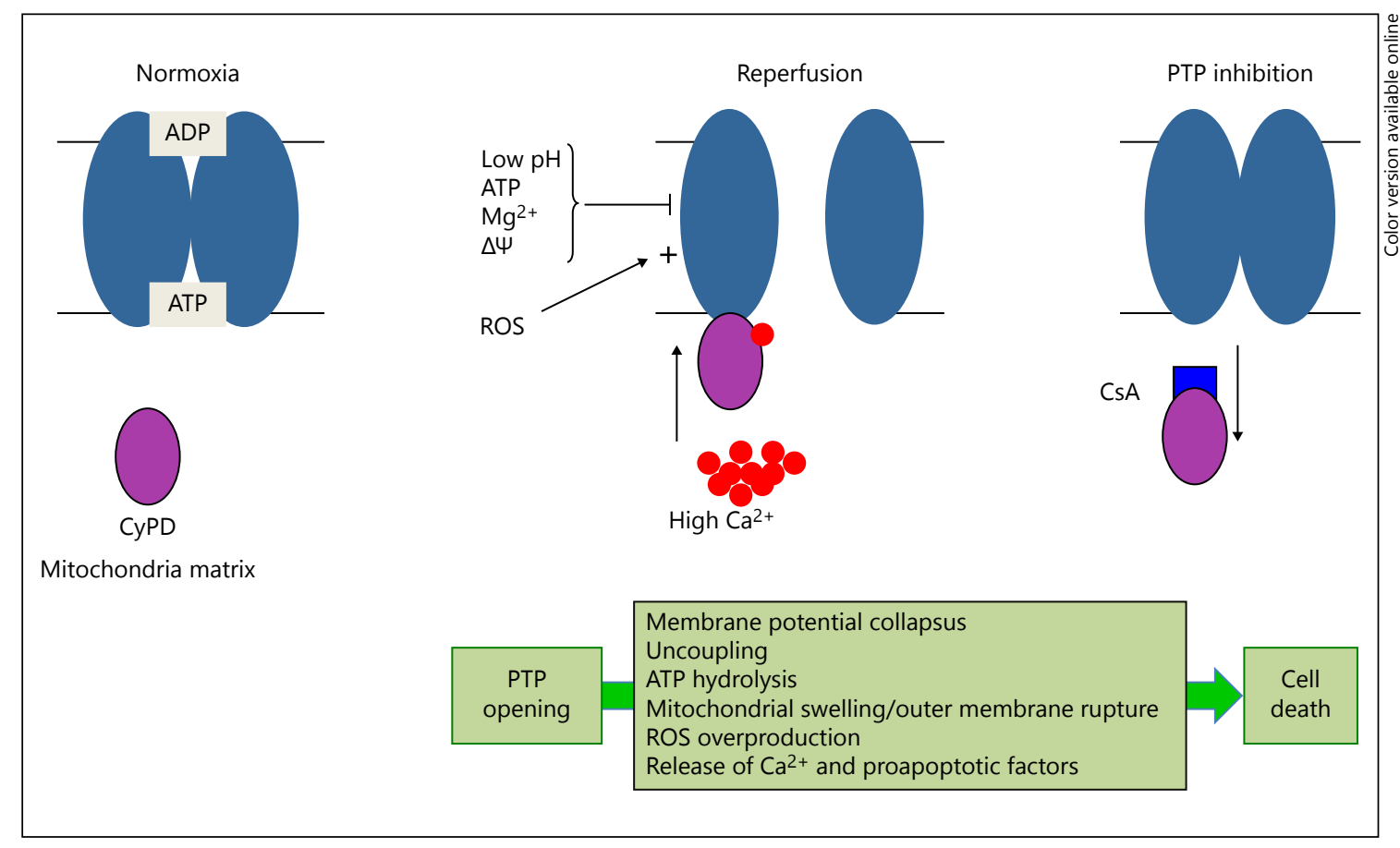

Fig. 1. Schematic representation of cyclosporine inhibiting PTP opening. PTP is in a closed conformation under normoxic conditions. At the time of reperfusion following prolonged ischemia, accumulation of $\mathrm{Ca}^{2+}$ in the mitochondrial matrix triggers the translocation of the matrix chaperone CyPD to the inner mito-

In 2003, Zhao et al. [15] showed that comparable protection could be achieved by altering the conditions of reperfusion. Mimicking the initial experiment by Murry et al. [61], they applied the brief cycles of ischemic reperfusion immediately after (but not before) the sustained ischemic insult; this intervention resulted in a significant infarct size reduction, and they named this phenomenon 'ischemic postconditioning'. This finding was confirmed by several other groups [62]. In a randomized, controlled, multicenter study, our group first reported that ischemic postconditioning can limit infarct size in ST-elevation myocardial infarction patients [63]. Briefly, the application of 4 episodes of $1 \mathrm{~min}$ inflation (obstruction of the coronary artery) and $1 \mathrm{~min}$ deflation (reperfusion) of the angioplasty balloon was associated with a $36 \%$ myocardial infarct size reduction [64]. Several phase II trials confirmed these findings [65]. However, other studies failed to find a beneficial effect of ischemic postconditioning during myocardial ischemia $[66,67]$.

In the brain, retrospective and prospective studies have shown that previous transient ischemic attack (TIA) attenuated subsequent stroke with smaller infarct size chondrial membrane that in turns contributes to set the PTP in its open conformation. Cyclosporine detaches CyPD from the inner membrane and thereby prevents PTP opening (adapted from Nicolli et al. [45]). and less clinical deficits compared with patients without a preceding transient event [68-71].

In the last 2 decades, our knowledge concerning the underlying molecular basis of postconditioning has substantially improved, and there is hope to potentially mimic the endogenous neuroprotective state in patients with a high risk of cerebral ischemia. This mechanism may promote plastic neuronal changes allowing better tolerance to ischemic insult in animal models [72]. By using a MCAO model of TIA in rats, Malhotra et al. [73] showed that erythropoietin and its receptor were upregulated by IP in the ipsilateral hemisphere by $24 \mathrm{~h}$ after IP.

The putative mechanisms of preconditioning may also include inhibiting ROS activities, overexpression of heat shock proteins, immediate-early gene expression, synthesis of new proteins, inflammation inhibition, increase of anti-apoptotic proteins and activation of Akt pathways, a signal transduction mechanism that promotes survival and growth in response to extracellular signals [74-77]. However, the clinical application of preconditioning is very limited due to the fact that the occurrence of most strokes is unpredictable. 


\section{Remote Conditioning}

Different modalities of 'conditioning' interventions have proved to be capable of preventing reperfusion injury. One of the most intriguing is 'remote conditioning'. Przyklenk et al. [78] initially observed that brief episodes of ischemic reperfusion applied to the circumflex coronary artery were able to protect the left anterior descending artery territory from ischemic reperfusion injury. This suggests that the protection could be 'transferred' remote from the initial site of injury. Numerous experimental and phase II clinical trials have confirmed this observation [79]. One popular experimental set up in patients consists of applying 4 episodes of 5 min brachial cuff inflation (i.e., brief ischemia) interspersed by $5 \mathrm{~min}$ cuff deflation (brief reperfusion) prior to a prolonged heart, kidney, liver or brain ischemia; as a result, these organs develop significantly smaller infarcts [80]. The mechanism of this intriguing phenomenon remains poorly understood, but appears to require either a neural or a humoral pathway $[81,82]$.

In acute IS, remote preconditioning has recently been applied during ambulance transportation to the hospital [83]. An open-label blinded outcome proof-of-concept study of pre-hospital, paramedic-administered $\mathrm{rPerC}$ at a 1:1 ratio in consecutive patients with suspected acute stroke. After neurological examination and MRI, patients with verified stroke who received alteplase treatment were included, and they received MRI at $24 \mathrm{~h}$ and 1 month and clinical re-examination after 3 months. The primary end point was penumbral salvage, defined as the volume of the perfusion-diffusion mismatch not progressing to infarction after 1 month approach showed no global statistically significant effect on penumbral salvage, infarct size or infarct progression as measured by MRI. However, when adjusted for baseline severity of hypoperfusion, a voxel-by-voxel analysis demonstrated increased tissue survival after 1 month suggesting that interventions targeting lethal reperfusion injury may be neuroprotective.

\section{Clinical Assessment of CsA in Reperfusion Injury}

Ischemic Stroke

In a pilot phase II clinical trial, our group recently examined 127 IS patients to find whether IV administration of cyclosporine in combination with thrombolysis might reduce cerebral infarct size [84]. Patients, presenting with an anterior circulation stroke and eligible for thrombolytic therapy, were enrolled in this multicenter, singleblinded, controlled trial. Fifteen minutes after randomization, patients received either an IV bolus injection of
$2.0 \mathrm{mg} / \mathrm{kg}$ CsA or placebo. This low dose was chosen after analysis of experimental IS data in murine models. CsA is effective between 0.6 and $2.4 \mathrm{mg}$, the neuroprotective effect disappears at higher concentrations $(>6 \mathrm{mg})$, which is associated with neurotoxicity [18].

The primary end point was infarct volume on MRI at 30 days. Secondary end points included infarct volume according to the site (proximal/distal) of arterial occlusion and recanalization after thrombolysis. When considering the whole study population, the reduction of infarct volume in the CsA compared with the control group was not significant. However, in the subgroup of patients with proximal occlusion and effective recanalization, infarct volume was significantly reduced in the cyclosporine compared with the control group.

\section{Myocardial Infarction}

We recently published the results of the CIRCUS trial that investigated the ability of CsA to improve clinical outcomes of ST elevation myocardial infarction in patients [85]. A total of 395 patients in the cyclosporine group and 396 in the placebo group received the assigned study drug and had data that could be evaluated for the primary outcome at 1 year. The rate of the primary outcome was $59.0 \%$ in the cyclosporine group and $58.1 \%$ in the control group (OR 1.04; 95\% CI 0.78-1.39; $\mathrm{p}=0.77)$. Cyclosporine did not reduce the incidence of the separate clinical components of the primary outcome or other events, including recurrent infarction, unstable angina and stroke. No significant difference in the safety profile was observed between the 2 treatment groups.

In patients with anterior STEMI who had been referred for primary PCI, IV cyclosporine did not result in better clinical outcomes than those with placebo and did not prevent adverse left ventricular remodeling at 1 year.

\section{CsA, Future Studies in IS}

The absence of effect of CsA in the heart, in this specific clinical setting, does not preclude the potential efficacy of CsA in IS patients. Based on our encouraging recent phase II study results, we are therefore currently designing a phase III trial combining thrombectomy and CsA within the $6 \mathrm{~h}$ time window in patients with proximal occlusion with a dose similar to that of the phase II trial.

\section{Imaging and Reperfusion Injury}

Although it is undoubtedly a major progress, the recent advance in reperfusion therapy by intra-arterial thrombectomy, brings into light the issue of reperfusion 
injury, with more patients being now exposed to this specific type of injury. We therefore need to measure reperfusion injury not only as part of the prognosis evaluation but also examine the impact of neuroprotective agents. HT and vasogenic edema are classical markers of reperfusion damage. Nevertheless, imaging methods revealing early and specific markers of reperfusion damage are currently insufficient. Hence, this area may deserve future research.

Post-Ischemic Hyperperfusion and Perfusion-

Weighted Imaging

Several animal studies suggest that the restoration of cerebral circulation consistently results in a hyperemic phase. Hyperemia may contribute to the development of reperfusion injury including via brain edema or hemorrhage. Furthermore, following post-ischemic hyperemia, a phase of secondary hypoperfusion can occur, which results in harmful effects on the reperfused tissue. Kidwell et al. [86] used perfusion-weighted (PW)-MRI to characterize hyperemia in 12 patients following intra-arterial thrombolysis. Hyperemia was visualized in 5 of 12 patients. On day 7, 79\% of voxels with hyperemia demonstrated infarction, whereas only $36 \%$ not showing hyperemia demonstrated infarction. Despite the voxel-by-voxel association of increased perfusion with infarction, there were no significant differences in the degree of clinical improvement in patients with regions of hyperemia versus those without. Recently, Yu et al. [87] using arterial spin labeling (ASL) showed that late ASL increased perfusion might predict high-grade HT. Larger future MRI studies are necessary to assess the extent to which hyperemia may result in unfavorable clinical outcome in human stroke.

Breakdown of the BBB and Contrast-Enhanced MRI

Pathological responses to ischemia in the microvasculature play a central role in the evolution of infarction; a critical event after ischemia is BBB breakdown [88].

The BBB impairment consists of complex ultrastructural disruptions, including damaged capillary endothelial cells, degeneration of astrocytes and pericytes, as well as perivascular edema [89]. Inhibition of microglial activation may protect the brain after IS by improving BBB viability and integrity [90]. Given these perspectives, it has become essential to assess BBB breakdown by optimal imaging methods.

Using a novel MRI marker that can detect BBB disruption, Latour et al. [91] studied a total of 144 acute stroke patients to test the association between reperfu- sion, HT and clinical outcome. BBB disruption was more common in patients who reperfused than in patients who did not reperfuse. In the reperfused group, patients with BBB disruption were more likely to have a poor clinical outcome than those without disruption. The post-contrast enhancement of the cerebrospinal fluid in FLAIR images (termed hyperintense acute reperfusion marker, HARM) is also an established marker of early BBB disruption [92].

\section{Conclusion}

Although the concept of conditioning has been breached clinically in the cardiovascular setting, it has been investigated clinically to a lesser extent in the realm of neurological disease. Recent experimental and phase II clinical research has suggested potential neuroprotective properties of cyclosporine in acute IS. Although accumulating experimental and clinical research evidence are encouraging, further larger clinical trials are needed to demonstrate that CsA improves clinical outcome in acute IS patients.

\section{Acknowledgments}

All authors contributed to the writing of the article.

\section{Sources of Funding}

None.

\section{Disclosure Statement}

None.

References
1 Patel RD, Saver JL: Evolution of reperfusion therapies for acute brain and acute myocardial ischemia: a systematic, comparative analysis. Stroke 2013;44:94-98.

2 Tissue plasminogen activator for acute ischemic stroke. The national institute of neurological disorders and stroke rt-PA stroke study group. N Engl J Med 1995;333:15811587.

3 Broderick JP, Palesch YY, Demchuk AM, Yeatts SD, Khatri P, Hill MD, et al: Endovascular therapy after intravenous t-PA versus t-PA alone for stroke. N Engl J Med 2013;368:893903. 
4 Ciccone A, Valvassori L, Nichelatti M, Sgoifo A, Ponzio M, Sterzi R, et al: Endovascular treatment for acute ischemic stroke. N Engl J Med 2013;368:904-913.

5 Kidwell CS, Jahan R, Gornbein J, Alger JR, Nenov V, Ajani Z, et al: A trial of imaging selection and endovascular treatment for ischemic stroke. N Engl J Med 2013;368: 914-923.

6 Berkhemer OA, Fransen PS, Beumer D, van den Berg LA, Lingsma HF, Yoo AJ, et al: A randomized trial of intraarterial treatment for acute ischemic stroke. N Engl J Med 2015;372: 11-20.

7 Goyal M, Demchuk AM, Menon BK, Eesa M, Rempel JL, Thornton J, et al: Randomized assessment of rapid endovascular treatment of ischemic stroke. N Engl J Med 2015;372: 1019-1030.

8 Campbell BC, Mitchell PJ, Kleinig TJ, Dewey HM, Churilov L, Yassi N, et al: Endovascular therapy for ischemic stroke with perfusionimaging selection. N Engl J Med 2015;372: 1009-1018.

9 Saver JL, Goyal M, Bonafe A, Diener HC, Levy EI, Pereira VM, et al: Stent-retriever thrombectomy after intravenous t-PA vs. t-PA alone in stroke. N Engl J Med 2015;372:2285-2295.

10 Jovin TG, Chamorro A, Cobo E, de Miquel MA, Molina CA, Rovira A, et al: Thrombectomy within 8 hours after symptom onset in ischemic stroke. N Engl J Med 2015;372: 2296-2306.

11 Bai J, Lyden PD: Revisiting cerebral postischemic reperfusion injury: new insights in understanding reperfusion failure, hemorrhage, and edema. Int J Stroke 2015;10:143-152.

12 Aronowski J, Strong R, Grotta JC: Reperfusion injury: demonstration of brain damage produced by reperfusion after transient focal ischemia in rats. J Cereb Blood Flow Metab 1997;17:1048-1056.

13 Pan J, Konstas AA, Bateman B, et al: Reperfusion injury following cerebral ischemia: pathophysiology, MR imaging, and potential therapies. Neuroradiology 2007;49:93102.

14 Pundik S, Xu K, Sundararajan S: Reperfusion brain injury: focus on cellular bioenergetics. Neurology 2012;79(13 suppl 1):S44-S51.

15 Zhao ZQ, Corvera JS, Halkos ME, Kerendi F, Wang NP, Guyton RA, et al: Inhibition of myocardial injury by ischemic postconditioning during reperfusion: comparison with ischemic preconditioning. Am J Physiol Heart Circ Physiol 2003;285:H579-H588.

16 Schinzel AC, Takeuchi O, Huang Z, Fisher JK, Zhou Z, Rubens J, et al: Cyclophilin D is a component of mitochondrial permeability transition and mediates neuronal cell death after focal cerebral ischemia. Proc Natl Acad Sci U S A 2005; 102:12005-12010.

17 Leger PL, De Paulis D, Branco S, Bonnin P, Couture-Lepetit E, Baud O, et al: Evaluation of cyclosporine $\mathrm{A}$ in a stroke model in the immature rat brain. Exp Neurol 2011;230:5866.
18 Borlongan CV, Yu G, Matsukawa N, Xu L, Hess DC, Sanberg PR, Wang Y: Acute functional effects of cyclosporine-A and methylprednisolone treatment in adult rats exposed to transient ischemic stroke. Life Sci 2005;76: 1503-1512.

19 Hacke W, Kaste M, Bluhmki E, Brozman M, Dávalos A, Guidetti D, et al: Thrombolysis with alteplase 3 to 4.5 hours after acute ischemic stroke. N Engl J Med 2008;359:13171329.

20 Yang GY, Betz AL: Reperfusion-induced injury to the blood-brain barrier after middle cerebral artery occlusion in rats. Stroke 1994; 25:1658-1664; discussion 1664-1665.

21 Yemisci M, Gursoy-Ozdemir Y, Vural A, Can A, Topalkara K, Dalkara T: Pericyte contraction induced by oxidative-nitrative stress impairs capillary reflow despite successful opening of an occluded cerebral artery. Nat Med 2009;15:1031-1037.

22 del Zoppo GJ, Mabuchi T: Cerebral microvessel responses to focal ischemia. J Cereb Blood Flow Metab 2003;23:879-894.

23 Sims NR, Muyderman H: Mitochondria, oxidative metabolism and cell death in stroke. Biochim Biophys Acta 2010;1802:80-91.

24 Leung AW, Halestrap AP: Recent progress in elucidating the molecular mechanism of the mitochondrial permeability transition pore. Biochim Biophys Acta 2008;1777:946-952.

25 Saito A, Maier CM, Narasimhan P, et al: Oxidative stress and neuronal death/survival signaling in cerebral ischemia. Mol Neurobiol 2005;31:105-116.

$26 \mathrm{Li} \mathrm{J}, \mathrm{Ma} \mathrm{X}, \mathrm{Yu} \mathrm{W}$, et al: Reperfusion promotes mitochondrial dysfunction following focal cerebral ischemia in rats. PLoS One 2012; 7:e46498.

27 Sanderson TH, Reynolds CA, Kumar R, Przyklenk K, Hüttemann $\mathrm{M}$ : Molecular mechanisms of ischemia-reperfusion injury in brain: pivotal role of the mitochondrial membrane potential in reactive oxygen species generation. Mol Neurobiol 2013;47:923.

28 Reddy MK, Labhasetwar V: Nanoparticlemediated delivery of superoxide dismutase to the brain: an effective strategy to reduce ischemia-reperfusion injury. FASEB J 2009;23: 1384-1395.

29 Kahles T, Brandes RP: Which NADPH oxidase isoform is relevant for ischemic stroke? The case for nox 2. Antioxid Redox Signal 2013;18:1400-1417.

30 Diener HC, Lees KR, Lyden P, et al: NXY-059 for the treatment of acute stroke: pooled analysis of the SAINT I and II Trials. Stroke 2008; 39:1751-1758.

31 Chamorro A, Amaro S, Castellanos M, Segura T, Arenillas J, Martí-Fábregas J, et al: Safety and efficacy of uric acid in patients with acute stroke (URICO-ICTUS): a randomised, double-blind phase $2 \mathrm{~b} / 3$ trial. Lancet Neurol 2014;13:453-460

32 Llull L, Laredo C, Renú A, Pérez B, Vila E, Obach $\mathrm{V}$, et al: Uric acid therapy improves clinical outcome in women with acute ischemic stroke. Stroke 2015;46:2162-2167.

33 Griffiths EJ, Halestrap AP: Protection by cyclosporin A of ischemia/reperfusion-induced damage in isolated rat hearts. J Mol Cell Cardiol 1993;25:1461-1469.

34 Uchino H, Minamikawa-Tachino R, Kristián T, Perkins G, Narazaki M, Siesjö BK, Shibasaki F: Differential neuroprotection by cyclosporin A and FK506 following ischemia corresponds with differing abilities to inhibit calcineurin and the mitochondrial permeability transition. Neurobiol Dis 2002;10:219-233.

35 Uchino H, Elmér E, Uchino K, et al: Amelioration by cyclosporin $\mathrm{A}$ of brain damage in transient forebrain ischemia in the rat. Brain Res 1998;812:216-226.

36 Yoshimoto T, Siesjö BK: Posttreatment with the immunosuppressant cyclosporin $\mathrm{A}$ in transient focal ischemia. Brain Res 1999;839: 283-291.

37 Matsumoto S, Isshiki A, Watanabe $\mathrm{Y}$ et al: Restricted clinical efficacy of cyclosporin A on rat transient middle cerebral artery occlusion. Life Sci 2002;72:591-600.

38 Vachon P, Beaudry F, Marier JF, et al: Cyclosporin A in blood and brain tissue following intra-carotid injections in normal and strokeinduced rats. Brain Res 2002;943:1-8.

39 Domañska-Janik K, Buzañska L, Dłuzniewska J, et al: Neuroprotection by cyclosporin A following transient brain ischemia correlates with the inhibition of the early efflux of cytochrome $\mathrm{C}$ to cytoplasm. Brain Res Mol Brain Res 2004;121:50-59.

$40 \mathrm{Yu}$ G, Hess DC, Borlongan CV: Combined cyclosporine-A and methylprednisolone treatment exerts partial and transient neuroprotection against ischemic stroke. Brain Res 2004;1018:32-37.

41 Murozono M, Matsumoto S, Matsumoto E, et al: Neuroprotective and neurotoxic effects of cyclosporine A on transient focal ischemia in mdrla knockout mice. Eur J Pharmacol 2004; 498:115-118.

42 Muramatsu Y, Furuichi Y, Tojo N, et al: Neuroprotective efficacy of FR901459, a novel derivative of cyclosporin $\mathrm{A}$, in in vitro mitochondrial damage and in vivo transient cerebral ischemia models. Brain Res 2007;1149: 181-190.

43 Yuen CM, Sun CK, Lin YC, et al: Combination of cyclosporine and erythropoietin improves brain infarct size and neurological function in rats after ischemic stroke. J Transl Med 2011;9:141.

44 Cho TH, Aguettaz P, Campuzano O, et al: Pre- and post-treatment with cyclosporine A in a rat model of transient focal cerebral ischaemia with multimodal MRI screening. Int J Stroke 2013;8:669-674.

45 Nicolli A, Basso E, Petronilli V, Wenger RM, Bernardi P: Interactions of cyclophilin with the mitochondrial inner membrane and regulation of the permeability transition pore, and cyclosporin A-sensitive channel. J Biol Chem 1996;271:2185-2192. 
46 Lust WD, Taylor C, Pundik S, Selman WR, Ratcheson RA: Ischemic cell death: dynamics of delayed secondary energy failure during reperfusion following focal ischemia. Metab Brain Dis 2002;17:113-121.

47 Clark RK, Lee EV, White RF, Jonak ZL, Feuerstein GZ, Barone FC: Reperfusion following focal stroke hastens inflammation and resolution of ischemic injured tissue. Brain Res Bull 1994;35:387-392.

48 Hausenloy DJ, Duchen MR, Yellon DM: Inhibiting mitochondrial permeability transition pore opening at reperfusion protects against ischaemia-reperfusion injury. Cardiovasc Res 2003;60:617-625.

49 Osman MM, Lulic D, Glover L, Stahl CE, Lau $\mathrm{T}$, van Loveren $\mathrm{H}$, et al: Cyclosporine- $\mathrm{A}$ as a neuroprotective agent against stroke: its translation from laboratory research to clinical application. Neuropeptides 2011;45:359368.

50 Kaminska B, Gaweda-Walerych K, Zawadzka M: Molecular mechanisms of neuroprotective action of immunosuppressants - facts and hypotheses. J Cell Mol Med 2004;8:4558.

51 Ziegler G, Harhausen D, Schepers C, Hoffmann O, Röhr C, Prinz V, et al: TLR2 has a detrimental role in mouse transient focal cerebral ischemia. Biochem Biophys Res Commun 2007;359:574-579.

52 Tang SC, Arumugam TV, Xu X, Cheng A, Mughal MR, Jo DG, Lathia JD, et al: Pivotal role for neuronal toll-like receptors in ischemic brain injury and functional deficits Proc Natl Acad Sci U S A 2007;104:1379813803

53 Heusch G, Musiolik J, Gedik N, Skyschally A: Mitochondrial STAT3 activation and cardioprotection by ischemic postconditioning in pigs with regional myocardial ischemia/reperfusion. Circ Res 2011;109:1302-1308.

54 Skyschally A, van Caster P, Boengler K, Gres $\mathrm{P}$, Musiolik J, Schilawa D, et al: Ischemic postconditioning in pigs: no causal role for RISK activation. Circ Res 2009;104:15-18.

55 Hausenloy DJ, Lim SY, Ong SG, Davidson SM, Yellon DM: Mitochondrial cyclophilin$\mathrm{D}$ as a critical mediator of ischaemic preconditioning. Cardiovasc Res 2010;88:67-74.

56 Karmazyn M: The 1990 Merck Frosst Award. Ischemic and reperfusion injury in the heart. Cellular mechanisms and pharmacological interventions. Can J Physiol Pharmacol 1991; 69:719-730.

57 Hausenloy DJ, Maddock HL, Baxter GF, Yellon DM: Inhibiting mitochondrial permeability transition pore opening: a new paradigm for myocardial preconditioning? Cardiovasc Res 2002;55:534-543.

58 Hausenloy DJ, Duchen MR, Yellon DM: Inhibiting mitochondrial permeability transition pore opening at reperfusion protects against ischaemia-reperfusion injury. Cardiovasc Res 2003;60:617-625.

59 Shanmuganathan S, Hausenloy DJ, Duchen MR, Yellon DM: Mitochondrial permeability transition pore as a target for cardioprotection in the human heart. Am J Physiol Heart Circ Physiol 2005;289:H237-H242.

60 Redell JB, Zhao J, Dash PK: Acutely increased cyclophilin A expression after brain injury: a role in blood-brain barrier function and tissue preservation. J Neurosci Res 2007;85:19801988.

61 Murry CE, Jennings RB, Reimer KA: Preconditioning with ischemia: a delay of lethal cell injury in ischemic myocardium. Circulation 1986;74:1124-1136.

62 Argaud L, Gateau-Roesch O, Raisky O, Loufouat J, Robert D, Ovize M: Postconditioning inhibits mitochondrial permeability transition. Circulation 2005;111:194-197.

63 Staat P, Rioufol G, Piot C, Cottin Y, Cung TT, L'Huillier I, et al: Postconditioning the human heart. Circulation 2005;112:2143-2148.

64 Thibault H, Piot C, Staat P, Bontemps L, Sportouch C, Rioufol G, et al: Long-term benefit of postconditioning. Circulation 2008; 117 : 1037-1044.

65 Heusch G, Libby P, Gersh B, Yellon D, Böhm M, Lopaschuk G, et al: Cardiovascular remodelling in coronary artery disease and heart failure. Lancet 2014;383:1933-1943.

66 Høfsten DE, Kelbæk H, Helqvist S, Kløvgaard L, Holmvang L, Clemmensen P, et al: The third Danish study of optimal acute treatment of patients with ST-segment elevation myocardial infarction: ischemic postconditioning or deferred stent implantation versus conventional primary angioplasty and complete revascularization versus treatment of culprit lesion only: rationale and design of the DANAMI 3 trial program. Am Heart J 2015;169:613621.

67 Limalanathan S, Andersen GØ, Kløw NE, Abdelnoor M, Hoffmann P, Eritsland J: Effect of ischemic postconditioning on infarct size in patients with ST-elevation myocardial infarction treated by primary PCI results of the POSTEMI (postconditioning in ST-elevation myocardial infarction) randomized trial. J Am Heart Assoc 2014;3:e000679.

68 Dirnagl U, Simon RP, Hallenbeck JM: Ischemic tolerance and endogenous neuroprotection. Trends Neurosci 2003;26:248-254.

69 Weih M, Kallenberg K, Bergk A, et al: Attenuated stroke severity after prodromal TIA: a role for ischemic tolerance in the brain? Stroke 1999;30:1851-1854.

70 Wegener S, Gottschalk B, Jovanovic V, et al: Transient ischemic attacks before ischemic stroke: preconditioning the human brain? A multicenter magnetic resonance imaging study. Stroke 2004;35:616-621.

71 Sitzer M, Foerch C, Neumann-Haefelin T, et al: Transient ischaemic attack preceding anterior circulation infarction is independently associated with favourable outcome. J Neurol Neurosurg Psychiatry 2004;75:659-660.

72 Sommer C: Neuronal plasticity after ischemic preconditioning and TIA-like preconditioning ischemic periods. Acta Neuropathol 2009; 117:511-523.
73 Malhotra S, Savitz SI, Ocava L, Rosenbaum DM: Ischemic preconditioning is mediated by erythropoietin through PI-3 kinase signaling in an animal model of transient ischemic attack. J Neurosci Res 2006;83:19-27.

74 Osaki M, Oshimura M, Ito H: PI3K-Akt pathway: its functions and alterations in human cancer. Apoptosis 2004;9:667-676.

75 Glantz L, Avramovich A, Trembovler V, et al: Ischemic preconditioning increases antioxidants in the brain and peripheral organs after cerebral ischemia. Exp Neurol 2005;192:117124.

76 Perez-Pinzon MA, Dave KR, Raval AP: Role of reactive oxygen species and protein kinase $\mathrm{C}$ in ischemic tolerance in the brain. Antioxid Redox Signal 2005;7:1150-1157.

77 Chen J, Graham SH, Zhu RL, Simon RP: Stress proteins and tolerance to focal cerebral ischemia. J Cereb Blood Flow Metab 1996;16: 566-577.

78 Przyklenk K, Bauer B, Ovize M, Kloner RA, Whittaker P: Regional ischemic 'preconditioning' protects remote virgin myocardium from subsequent sustained coronary occlusion. Circulation 1993;87:893-899.

79 Sloth AD, Schmidt MR, Munk K, Schmidt M, Pedersen L, Sørensen HT, et al: Impact of cardiovascular risk factors and medication use on the efficacy of remote ischaemic conditioning: post hoc subgroup analysis of a randomised controlled trial. BMJ Open 2015;5:e006923.

80 Heusch G, Bøtker HE, Przyklenk K, Redington A, Yellon D: Remote ischemic conditioning. J Am Coll Cardiol 2015;65:177-195.

81 Lim SY, Yellon DM, Hausenloy DJ: The neural and humoral pathways in remote limb ischemic preconditioning. Basic Res Cardiol 2010;105:651-655.

82 Przyklenk K, Whittaker P: Remote ischemic preconditioning: current knowledge, unresolved questions, and future priorities. J Cardiovasc Pharmacol Ther 2011;16:255-259.

83 Hougaard KD, Hjort N, Zeidler D, et al: Remote ischemic perconditioning as an adjunct therapy to thrombolysis in patients with acute ischemic stroke: a randomized trial. Stroke 2014;45:159-167.

84 Nighoghossian N, Berthezène Y, Mechtouff L, Derex L, Cho TH, Ritzenthaler T, et al: Cyclosporine in acute ischemic stroke. Neurology 2015;84:2216-2223.

85 Cung TT, Morel O, Cayla G, Rioufol G, Garcia-Dorado D, Angoulvant D, et al: Cyclosporine before $\mathrm{PCI}$ in patients with acute myocardial infarction. N Engl J Med 2015;373:10211031.

86 Kidwell CS, Saver JL, Mattiello J, et al: Diffusion-perfusion MRI characterization of postrecanalization hyperperfusion in humans. Neurology 2001;57:2015-2021.

$87 \mathrm{Yu} \mathrm{S}$, Liebeskind DS, Dua S, Wilhalme $\mathrm{H}$, Elashoff D, Qiao XJ, et al: Postischemic hyperperfusion on arterial spin labeled perfusion MRI is linked to hemorrhagic transformation in stroke. J Cereb Blood Flow Metab 2015;35: 630-637. 
88 Hawkins BT, Davis TP: The blood-brain barrier/neurovascular unit in health and disease. Pharmacol Rev 2005;57:173-185.

89 Garbuzova-Davis S, Rodrigues MC, Hernandez-Ontiveros DG, et al: Blood-brain barrier alterations provide evidence of subacute diaschisis in an ischemic stroke rat model. PLoS One 2013;8:e63553.
90 Yenari MA, Xu L, Tang XN, Qiao Y, Giffard RG: Microglia potentiate damage to bloodbrain barrier constituents: improvement by minocycline in vivo and in vitro. Stroke 2006; 37:1087-1093.

91 Latour LL, Ezzeddine MA, Chalela JA, Warach S: Early blood-brain barrier disruption in human focal brain ischemia. Ann Neurol 2004;56:468-477.
92 Warach S, Latour LL: Evidence of reperfusion injury, exacerbated by thrombolytic therapy, in human focal brain ischemia using a novel imaging marker of early blood-brain barrier disruption. Stroke 2004;35(11 suppl 1):26592661. 